\title{
Ketoalkalosis: Masked Presentation of Diabetic Ketoacidosis With Literature Review
}

\author{
Vinod Kumar ${ }^{\mathrm{a}}$, Sushant M. Nanavatia, c, Fnu Komal ${ }^{\mathrm{a}}$, Luis Carlos Ortiz ${ }^{\mathrm{a}}$, \\ Namrata Paul ${ }^{\mathrm{a}}$, Manhedar Kumarb ${ }^{\mathrm{b}}$, Patrick Michael ${ }^{\mathrm{a}}$, \\ Monisha Singhal
}

\begin{abstract}
Most dreaded complication in type 1 diabetes mellitus remains diabetic ketoacidosis (DKA): plasma blood glucose $>250 \mathrm{mg} / \mathrm{dL}$, serum bicarbonate $<18 \mathrm{mEq} / \mathrm{L}$, anion gap metabolic acidosis and ketosis. Insulin deficiency with high levels of glucagon and stress hormones causing ketogenesis in liver, elevated lipolysis in peripheral tissues, and increased free fatty acids contribute the formation of ketones leading to metabolic acidosis. And hence DKA is also termed as ketoacidosis. Unusually, patients with diuretic use, alkali ingestion, intractable vomiting, or hypercortisolism may present with alkalemia in DKA. Contraction (Metabolic) Alkalosis masquerades metabolic acidosis with anion gap and low to normal bicarbonate that uncovers on provision of intravenous fluids. We present a case of a 25 -year-old female with DKA presenting with intractable vomiting, alkalotic $\mathrm{pH}$ and high anion gap.
\end{abstract}

Keywords: Ketoalkalosis; Type 1 diabetes; Diabetic ketoacidosis; Vomiting; Metabolic alkalosis; High anion gap

\section{Introduction}

Diabetic ketoacidosis (DKA) remains the most dreaded complications of type 1 diabetes mellitus (T1DM). Non-adherence to insulin, concomitant infections, or new diagnosis of DKA ensues in the uninhibited production of ketones and chaotic metabolic state with hyperglycemia, ketoacidosis and ketonuria. DKA is defined as blood glucose greater than $250 \mathrm{mg} / \mathrm{dL}$, blood $\mathrm{pH}$ less than 7.3, serum bicarbonate less than $18 \mathrm{mEq} / \mathrm{L}$ and elevated anion gap metabolic acidosis. Atypically use of diuretic, intractable vomiting, or hypercortisolism may present with alkalemia in DKA. On presentation, these patients' acido-

Manuscript submitted November 21, 2017, accepted November 29, 2017

aDepartment of Internal Medicine, St. Joseph's University Medical Center, Paterson, NJ, USA

bDepartment of Hematology \& Oncology, St. Joseph's University Medical Center, Paterson, NJ, USA

${ }^{\mathrm{c} C o r r e s p o n d i n g ~ A u t h o r: ~ S u s h a n t ~ M . ~ N a n a v a t i, ~ D e p a r t m e n t ~ o f ~ I n t e r n a l ~ M e d i-~}$ cine, St. Joseph's University Medical Center, Xavier 5, 703 Main Street, Paterson, NJ 07503, USA. Email: snanav2@gmail.com

doi: https://doi.org/10.14740/jem472w sis would be masqueraded by alkalosis. We present a unique case of 25 years old female with DKA and alkalemia.

\section{Case Report}

A 25-year-old female with type 1 diabetes mellitus presented with complaints of intractable vomiting, generalized weakness and abdominal pain. Six hours prior to arrival to emergency department (ED), she started to experience diffuse abdominal pain around periumbilical area and subsequently started intractable non-bilious vomiting. At home, she was prescribed to insulin detemir 25 units once a day along with insulin aspart 6 units along with three meals. She stated of adherent to insulin dosages, but missed the morning dose. On admission, she was lethargic, dry mucous and oral mucosa, Kussmaul respiration and intense periumbilical pain. Patient was afebrile, blood pressure $107 / 58 \mathrm{~mm} \mathrm{Hg}$, respiratory rate 26 breaths/min, pulse 99 beats/min, and oxygen saturation $99 \%$ on ambient air. Electrocardiogram interpreted normal sinus rhythm with rate of 86 beats/min with QT corrected prolongation of $507 \mathrm{~ms}$.

Initial laboratory investigations included blood glucose $534 \mathrm{mg} / \mathrm{dL}$, serum sodium $133 \mathrm{mEq} / \mathrm{dL}$, chloride $93 \mathrm{mEq} / \mathrm{dL}$, potassium $5.1 \mathrm{mEq} / \mathrm{dL}$, creatinine $0.94 \mathrm{mg} / \mathrm{dL}$, bicarbonate 20 $\mathrm{mEq} / \mathrm{dL}$, albumin $3.5 \mathrm{~g} / \mathrm{dL}$, white blood cells $7,100 / \mathrm{mm}^{3}$, hemoglobin $10.1 \mathrm{~g} / \mathrm{dL}$, platelets $273,000 / \mathrm{mm}^{3}$, magnesium 1.6 $\mathrm{mg} / \mathrm{dL}$, lactic acid $1.5 \mathrm{mmol} / \mathrm{L}$ and serum ketones large positive. Blood gas analysis showed $\mathrm{pH} 7.43, \mathrm{pCO}_{2} 28 \mathrm{~mm} \mathrm{Hg}$, and bicarbonate $19 \mathrm{mmol} / \mathrm{L}$. Urinalysis showed high ketones and urine glucose $>500 \mathrm{mg} / \mathrm{dL}$.

Treatment with intravenous (IV) saline and replenishment of magnesium was started immediately, and insulin was given 8 units subcutaneously once. After receiving two liters of IV saline, patient was awake and alert and she was ordered to be given 10 units of long-acting insulin. On repeating metabolic panel in $5 \mathrm{~h}$, serum sodium level showed $130 \mathrm{mEq} / \mathrm{dL}$, potassium $3.3 \mathrm{mEq} / \mathrm{dL}$, chloride $102 \mathrm{mEq} / \mathrm{dL}$, bicarbonate $11 \mathrm{mEq} /$ $\mathrm{dL}$ and blood glucose $263 \mathrm{mg} / \mathrm{dL}$. Initial corrected anion gap for albumin was $21.25 \mathrm{mEq} / \mathrm{L}$ and subsequent anion gap improved to $18.75 \mathrm{mEq} / \mathrm{L}$. Blood gas analysis showed $\mathrm{pH} 7.27$, $\mathrm{pCO}_{2} 19 \mathrm{~mm} \mathrm{Hg}$, and bicarbonate $9 \mathrm{mmol} / \mathrm{L}$ (Table 1). Patient was upgraded to intensive care unit (ICU), initiated potassium IV supplements, and started on dextrose 5\% water-normal saline $150 \mathrm{~mL} / \mathrm{h}$. After receiving potassium, she was started on insulin 2 units hourly via IV. Following $8-10 \mathrm{~h}$, patient's ab- 
Table 1. Laboratory Investigations at the Time of Admission and After IV Fluids Resuscitation

\begin{tabular}{lll} 
& A: at the time of admission & B: after IV fluids resuscitation \\
\hline Arterial $\mathrm{pH}(7.37-7.45)$ on blood gas & 7.43 & 7.27 \\
$\mathrm{PaCO}_{2}(\mathrm{~mm} \mathrm{Hg})$ on blood gas & 28 & 19 \\
Bicarbonate $(\mathrm{mmol} / \mathrm{L})$ & 19 & 9 \\
Sodium $(\mathrm{mEq} / \mathrm{L})$ & 133 & 130 \\
Potassium $(\mathrm{mEq} / \mathrm{L})$ & 5.1 & 3.3 \\
Chloride $(\mathrm{mEq} / \mathrm{L})$ & 93 & 102 \\
Bicarbonate $(\mathrm{mEq} / \mathrm{L})$ & 20 & 11 \\
Blood urea nitrogen $(\mathrm{mg} / \mathrm{dL})$ & 23 & 23 \\
Creatinine $(\mathrm{mg} / \mathrm{dL})$ & 0.94 & 0.83 \\
Glucose $(\mathrm{mg} / \mathrm{dL})$ & 534 & 263 \\
Corrected anion gap & 21.25 & 18.75 \\
Albumin $(\mathrm{g} / \mathrm{dL})$ & 3.5 & 3.3 \\
\hline
\end{tabular}

Showing point A: hyperglycemia with blood sugar of 534 , corrected AG of 21 , alkalemic $\mathrm{pH}$ and bicarbonate of 20 . Point B shows improvement in anion gap and blood sugar after administration of IV fluids; however, we can clearly see pH becomes more acidotic and patient develops more severe metabolic acidosis meeting all four criteria for the diagnosis of DKA.

dominal pain was resolving, no episodes of emesis, attentive and urged to eat. Her blood glucose was $198 \mathrm{mg} / \mathrm{dL}$, received 12 units of long acting insulin and IV insulin was discontinued after $1 \mathrm{~h}$. Order for short-acting insulin 10 units with meal was placed as she tolerated diet. Subsequently, she was transferred to medical floor once deemed stable. After course of $36 \mathrm{~h}$, she was discharged with long acting insulin 16 units twice daily along with 8 units with meals.

\section{Discussion}

DKA provoked by the lack of insulin and uninhibited levels of glucagon causes ketogenesis in the liver. This further leads to lipolysis in the peripheral tissues leading to production of free fatty acids and formation of ketone bodies, such as 3-hydroxybutyrate and acetoacetic acid, conjuring acidic $\mathrm{pH}$ [1].

Previously there have been publications reporting prevalence of combined acid-base disorders in DKA as high as $47.5 \%$, and of which, most common was metabolic alkalosis [2].

In patients presenting with DKA, they commonly present with profuse vomiting. Intractable vomiting in these patients causes development of fluid volume contraction alkalosis. Vomiting causes chloride depletion that indirectly stimulates bicarbonate resorption and decreasing secretion in the collecting ducts of the kidneys. Additionally, it causes excretion of potassium in the kidneys eliciting the activation of the reninaldosterone axis resulting in bicarbonate reabsorption $[1,2]$. With volume depletion, resulting hyperaldosteronism induces exchange of sodium ions for potassium ions or hydrogen ions. This chaotic metabolic interplay results in state of alkalemia. In case series by Svart et al, they observed six patients with diabetic ketoalkalosis; all six patients had commonly associated symptoms of severe nausea and vomiting [3]. There is also evidence that patients having autonomic neuropathy such as gastroparesis due to poorly controlled diabetes, usually pre- sent with recurrent vomiting [4].

High anion gap, usually seen in DKA, is associated with an increase by the addition of new anions, such as lactic acid. In our case, patient had a high anion gap with normal lactate and marked alkalosis.

Treatment of diabetic ketoalkalosis does not differ from the conventional management of DKA. These patients should be treated with aggressive IV fluids, electrolytes supplementation (especially potassium), and hourly IV insulin. Administration of IV fluids remains of utmost priority with timely replenishment of electrolytes. In case reported by Jerrard et al, adding potassium to an IV saline solution aid in quickly reversing the alkalotic state [5].

This case illustrates patients in DKA may present with severe dehydration from vomiting leading coexistence of multiple metabolic derangement, systematic blood gas analysis, and normal or high $\mathrm{pH}$. We hope our case helps to improve index of suspicion with prompt diagnosis and medical treatment in DKA.

\section{Acknowledgments}

We would express deep gratitude to Dr. Chandra Chandran and Dr. Gibiezaite for their expert advice and encouragement.

\section{Conflict of Interest}

There is no conflict of interest to be disclosed for any authors of this paper.

\section{References}

1. Kamel KS, Halperin ML. Acid-base problems in diabetic 
ketoacidosis. N Engl J Med. 2015;372(20):1969-1970.

2. Elisaf MS, Tsatsoulis AA, Katopodis KP, Siamopoulos KC. Acid-base and electrolyte disturbances in patients with diabetic ketoacidosis. Diabetes Res Clin Pract. 1996;34(1):23-27.

3. Watanabe Y, Noda K, Akazawa K, Fukuyama J. Two cases of type 1 diabetic women with diabetic ketoacidosis presenting as alkalaemia. Diabetes Res Clin Pract. 2009;83(2):e54-57.

4. Svart MV, Voss TS, Bayat M, Madsen LR, Andersen LT, Poulsen PL, Moller N. Rare presentations of ketoacidosis: diabetic ketoalkalosis and ketoacidosis secondary to fasting and muscular dystrophy. Clin Diabetes. 2015;33(1):37-39.

5. Jerrard D, Hanna J. Diabetic ketoacidosis with alkalemia. Am J Emerg Med. 2001;19(6):521-522. 